\title{
Supporting Make or Buy Decision for Reconfigurable Manufacturing System, in Multi-site Context
}

\author{
Youssef Benama ${ }^{1, *}$, Thècle Alix ${ }^{2}$, and Nicolas Perry ${ }^{3}$ \\ ${ }^{1}$ University of Bordeaux, I2M, UMR5295, F-33400, France \\ ${ }^{2}$ University of Bordeaux, IMS, UMR-CNRS 2518, F-33400, France \\ ${ }^{3}$ Arts et Métiers ParisTech, I2M, UMR5295, F-33400, France \\ firstname.name@u-bordeaux.fr
}

\begin{abstract}
The make or buy decision is a strategic issue. When looking for finding out which components or products should be manufactured or externalized then buy, capacity for human and technical resources at the workshop level as well as costs of the externalization are key questions to be answered. In the case of mobile manufacturing systems that are movable between various locations, long term strategic aspects must be considered when addressing the make or buy decision problem. This paper aims to provide a structured make or buy decision model, adapted for reconfigurable manufacturing systems with strong mobility constraints. An industrial application case is provided to illustrate the presented method.
\end{abstract}

Keywords: Mobility, RMS, make or buy, multi-site context, MCDM.

\section{Introduction}

The make or buy decision problem also known as "sourcing", "outsourcing" or "subcontracting" problem, is among the most pervasive issues confronting modern organizations [1]. Making the right decision with regard to outsourcing can provide a major boost to a company's financial performance, although there is evidence that many companies do not achieve the advantages of outsourcing [2]. McIvor [3] demonstrates that decisions on outsourcing are rarely taken on the basis of particular strategic perspectives. Most of time the only intention is gaining short-term cost advantages [2].

The "make or buy" decision is a strategic decision and has implications for the overall corporate strategy of the organization by analyzing a number of strategic factors in case of short term cost reduction purpose, long-term strategic considerations, which have greater importance, should be considered [4]. Padillo[1] identified six disciplines covered by the make or buy problem: (1) industrial organization; (2) corporate/business strategy; (3) purchasing or supply management; (4) strategic operations management; (5) operations research; and (6) cost accounting or managerial economics.

\footnotetext{
* Corresponding author.

B. Grabot et al. (Eds.): APMS 2014, Part I, IFIP AICT 438, pp. 150-158, 2014.

(C) IFIP International Federation for Information Processing 2014
} 
Make or buy decision was argued most frequently by the economists. They have considered the "make or buy" problem especially with the perspective of costs. But the "make or buy" decision considerations should not only focus on costs [4]. Many authors, have noted the need to include multiple factors when performing a make or buy analysis [1]. They take into account strategic competitive performance, managerial performance, sourcing performance and financial performance. McIvor [5] proposed a model based on technical capability, comparison of internal and external capabilities, organization profiles and total acquisition costs.

On the other hand, manufacturing systems operating in a context characterized by: demand fluctuation, local production and site dependency, should cope with specifications such as mobility, scalability and functional adaptability. Those specifications allow fast and cost effectively adaptation to environment changes. In the literature, manufacturing systems meeting these specifications are referenced as Reconfigurable Manufacturing Systems (RMS) [6]-[9]. In the area of RMS, we notice a lack of models that takes into account the production system mobility, when addressing the "make or buy" problem. Furthermore, in multi-site context, a long term vision should be incorporated into the decision model in order to optimize the investments for the manufacturing mobile system respectively to the expected capacity and final product costs.

In the following sections we detail our proposed make or buy model adapted to RMS systems. Then, the industrial application case illustrates the model before concluding.

\section{The Proposed Make or Buy Model for RMS Systems}

The proposed decision model framework is adapted from the model proposed by van de Water and van Peet [2]. This framework highlights 3 decision model stages:

- Strategic analysis: the make or buy decision is based on the satisfaction of multiple objectives (e.g. cost, risk...). This stage deals with the importance of each objective. The given importance highlights the priorities of the decision maker. Decision situation has an impact on these priorities, for example, considering the purchasing situation classification presented by Faris [10].

- Alternative evaluation: this stage proposes a model to evaluate in house manufacturing or external sourcing alternatives. The evaluation model is based on indicators definition. Each of the four indicators proposed is depending on other parameters which we call attributes. This stage will be detailed in the next section.

- Providers selection: this stage is about contractual aspects in the provider selection process and collaboration nature definition. It's based on previous stage results. While our aim is to identify if manufacturing of a specified product will be achieved in house or via external sourcing. This stage is out of this paper scope. 


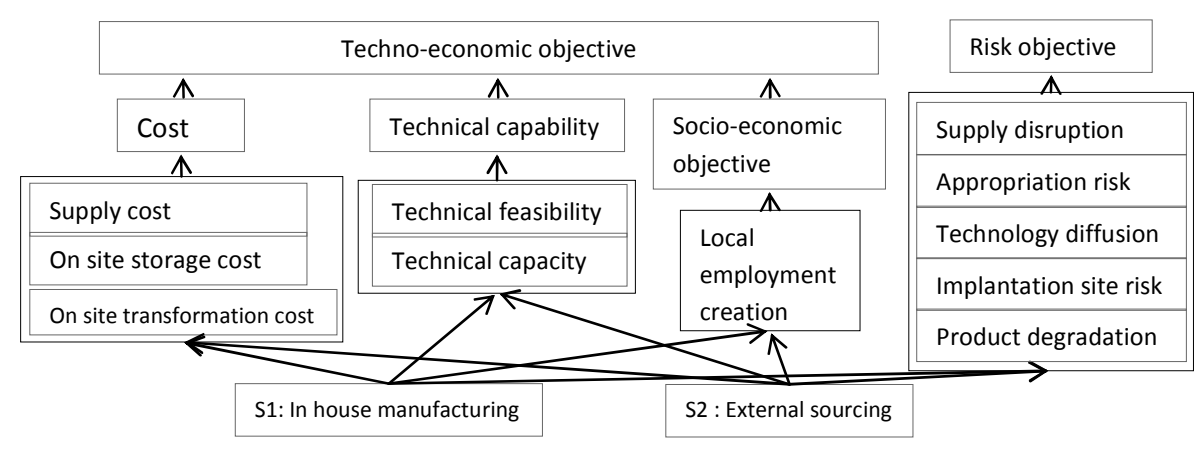

Fig. 1. Structure of the alternative's evaluation model

\subsection{Alternative Evaluation Model}

\section{Assessment of Techno-economic Objective}

\section{Cost evaluation}

We identify three attributes linked to cost objective. Supply cost (1): it takes into account material purchasing costs and shipping costs set from transportation costs and customs clearance fees. On site storage cost (2): it depends on component value, storage period and cost of all tools used in storage activity. On site transformation cost (3): concerns all costs linked to transformation operations and value added activities realized on site. For in house manufacturing case, it takes into account, machinery investment, cost relative to usual functioning like process configuration cost, maintenance cost and energy cost. In addition, for a mobile manufacturing system, the full workshop is shipped on site, so it's necessary to consider the shipping cost. On the other hand, external sourcing case concerns in most cases quality inspection operations when receiving materials, and reworking operations.

To assess the satisfaction of the cost objective, we use the satisfaction function proposed by Harrington [11] which appears to give satisfactory results in our case.

\section{Technical capability objective}

\section{Internal technical capability}

Internal technical feasibility describes the ability of in-house manufacturing alternative to ensure the know-how and process required to satisfy the product feasibility on site. It depends on:

System mobility: machinery and resources must be movable from one site to another.

Qualification availability: operators are needed to be hired locally.

Energy availability and accessibility: in the context of desertic location, energy accessibility may be difficult, that can limit the use of certain resources (welding...).

On the other hand, internal technical capacity is related to the ability to supply the necessary quantity of raw materials. Two factors are involved: (1) the availability of qualified suppliers, (2) their proximity from the geographical production location. 


\section{Supplier technical capability}

McIvor and Humphreys [5] identified 6 criteria to evaluate the technological capabilities of supplier, which include manufacturing capabilities, technical support, design capability, investment in $\mathrm{R} \& \mathrm{D}$, speed of development and new product introduction (NPI) rate. In our analysis, technical support, investment on R\&D and design capability are embedded in technical feasibility. On the other hand, manufacturing capability, speed of development and NPI rate determine the technical capacity of suppliers.

\section{Evaluation of technical capability satisfaction}

Evaluation of each technical capability factor is realized by giving notation between 0 and 1. Non-compensatory aggregation strategy is needed because the failure of one technical capability factor could not be compensated by the well performance of another factor. GOWA (Generalized Ordered Weighted Averaging) aggregation operator could be used to make aggregation [12].

\section{Socio-economic objective}

In the case of public projects where clients are governments or official institutes, socio-economic issues must be considered. Öncü stated that "A government concerned with economic growth cannot ignore the economic aspects of technology. Major purpose of national technology policy is the harnessing of technology to meet economic and social goals [...]. When one local-manufacture project is chosen rather than an import project, the choices have consequences for employment, [...]. Each local manufacture project will affect employment and wage payments." [4]. The socio-economic benefits in terms of promoting local employment have an impact on final decision. We propose to incorporate in our model a socio-economic objective, which is concerned with the direct employment creation. This objective will be directly linked to geographical production localization of the supplier: if the supplier is localized in the same country than client site, the satisfaction value is 1 , otherwise, the satisfaction value is 0.1 .

For a considered make or buy alternative, the assessment of the corresponding techno-economic objective is based on the aggregation of cost, technical capability and socio-economic objectives. For aggregation, we use GOWA operator [12]:

$$
T E 0_{i}\left(A_{j}\right)=\sqrt[s]{\omega_{T E O} * T E O_{i}^{S}+\omega_{R O} * R O_{i}^{s}}
$$

\section{Risk Objective}

\section{Identification of risk factors}

Padillo [1] identified 4 sourcing risk attributes: appropriation risk, technology diffusion risk, end-product degradation risk, and supply disruption risk. Appropriation and technology diffusion risks are relevant mostly for outsourcing alternatives. While Supply disruption is applicable to both in-house and outsourcing alternatives [1]. On the other side, end-product degradation risk is in relation with the outsourcing of an activity that is located between the firm and its customers. This type of risk is not present in our problem, but the risk about transportation activity remains dominant. Wagner [13] divided risk sources into five distinct classes: (1) demand side; 


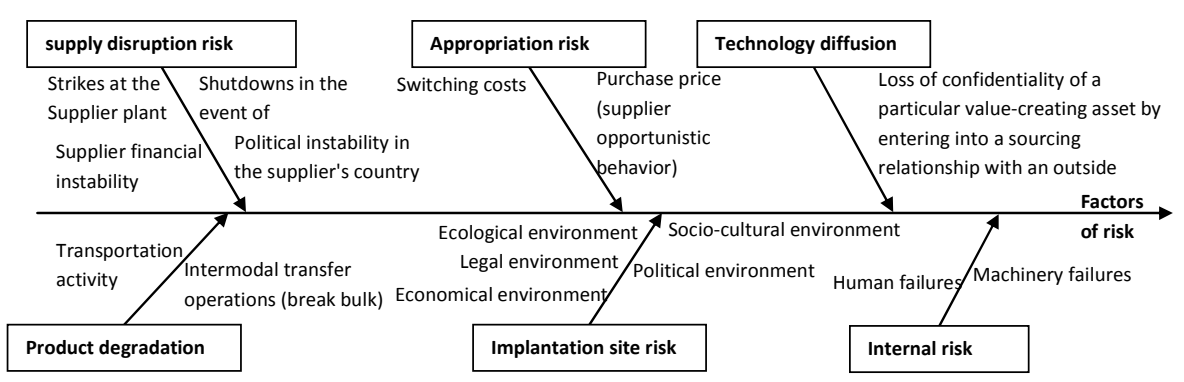

Fig. 2. Identification of risk factors

(2) supply side; (3) regulatory, legal and bureaucratic; (4) infrastructure; and (5) catastrophic. Srinivasan [14] focus on two types of factors that can impact the performance of supply chain, the first factors are internal to supply chain, which are demand and supply risks, like demand variability, lead-time variability supply delays, order cancellations, etc.). On the other hand, environment uncertainty which includes factors that are external to the supply chain. Those factors are strategic in nature, like, changes in product or process technology, competitor behavior, changes in consumer preferences, etc.

Production system mobility implies that the characteristics of the site where the production system will be implanted will vary. In consequent, the risk factors related to implantation site should be integrated in the analysis. We use a macro-environment analysis, like the PESTLE (Political, Economic, Social, Technological, Legal and Environmental analysis) approach to characterize risks related to the implantation site. In the other hand, either make or buy situations require realization of additional operations by the buying firm. Internal operations need human and machinery interventions and should be realized locally on site. In consequent, internal risks corresponding to human and machinery failures should be considered in both situations.

The assessment of each risk factor is firstly conducted using the FMECA (Failure Modes, Effects and Criticality Analysis). Each risk factor will be identified and quantified in term of likelihood of occurrence and in term of severity. Thereby, the overall risk criticality of will be defined by summing the corresponding criticality of risk factors. The next question is how to judge if the level of the risk criticality is acceptable or not. We define a satisfaction function that will express the preferences of the decision maker. We use Derringer function (Derringer, 1980); the decision maker expresses an interval of criticality levels among which the criticality level of the considered alternative will be acceptable.

\section{Performance Evaluation}

\section{Local Performance evaluation}

Local performance evaluation aims to find out the best alternative for each considered site localization. Each objective is evaluated as it was mentioned previously. The decision-maker should express it's preference between the importance of each 
objective. Aggregation of the local performance is made using the GOWA operator [12]. This operator allow the DM to adapt the aggregation strategy, i.e. if compensation will be considered or not, to each situation decision, by setting the trade-off strategy parameter. For each site $\mathrm{i}$, Local performance evaluation of alternative $\mathrm{j}$ is assessed:

$$
L P E_{i}\left(A_{j}\right)=\sqrt[s]{\omega_{T E O} * T E O_{i}^{S}+\omega_{R O} * R O_{i}^{S}}
$$

TEO : Technical and Economical Objective value. RO : Risk Objective value

\section{Global Performance evaluation}

Global Performance evaluation aims to determine the best alternative in regard to overall sites. First condition that should be verified is the importance of each site. For strategic reasons, like the willingness to enter a new market, or for reasons of market size. Global Performance Evaluation (GPE) of the alternative $\mathrm{j}$ is given by:

$$
\operatorname{GPE}\left(A_{j}\right)=\sqrt[s]{\sum_{i=1}^{n} \omega_{i} *\left(L P E_{i}\left(A_{j}\right)\right)^{s}}
$$

$\mathrm{n}$ : number of sites where the production system will operate. $\boldsymbol{\omega}_{\boldsymbol{i}}$ is the importance of the site i. $\boldsymbol{L P E}_{\boldsymbol{i}}\left(\boldsymbol{A}_{\boldsymbol{j}}\right)$ is the local performance evaluation of the alternative $j$, for the site $i$. $\mathrm{s}$ is the trade-off strategy parameter. All alternatives will be ranked following the GPE value, and then the best alternative will have the high GPE.

\section{Industrial Application}

The Industrial application concerns an enterprise E, operating in solar energy sector. For confidentiality reasons, real values have been changed, but hypotheses and assumptions remain valid. The component analyzed is a steel part obtained by bending process. This part is critical because it contributes to mechanical resistance of the endproduct. The production should be operated by the same reconfigurable manufacturing system sequentially on 5 different sites. The expected volume demands are: $\mathrm{S} 1=20000, \mathrm{~S} 2=18000, \mathrm{~S} 3=16000, \mathrm{~S} 4=5000, \mathrm{~S} 5=11000$. We consider 3 different alternatives. A1: part will be manufactured by the internal production system. A2: part will be realized by an external low cost supplier in Eastern Europe. A3: corresponds to an external supplier localized in North Africa.

\subsection{Stage 1: Strategic Analysis}

\section{Objective's Weighting}

Importance of each objective is set using a pairwise comparison. Therefore, the importance of each objective will be obtained by the eigenvector of the matrix: Cost Objective: 0.635 , Technical capability $=0.287$ and Socio-economical objective $=0.078$. In order to assess local performance for each site, technical and economical objective and risk objective will be considered with the same importance: $\omega_{\text {TCO }}=0.5$ and $\omega_{\text {Risk }}=0.5$. 


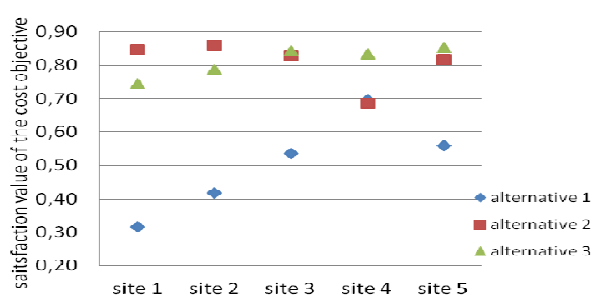

Fig. 3. Satisfaction of cost objective

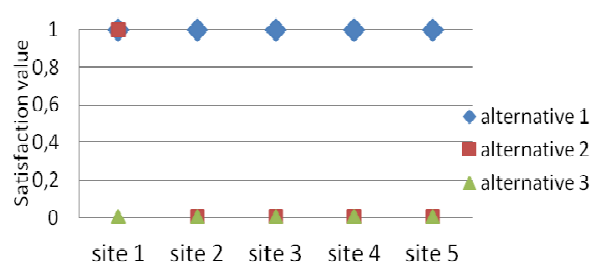

Fig. 5. Socio economic objective

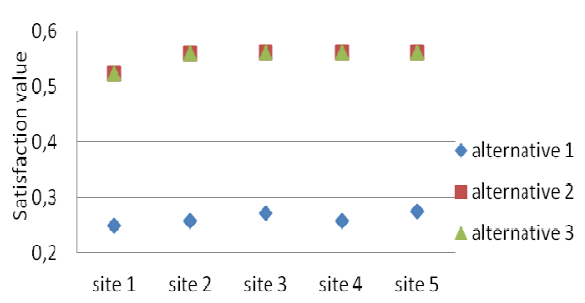

Fig. 4. Satisfaction of technical capability

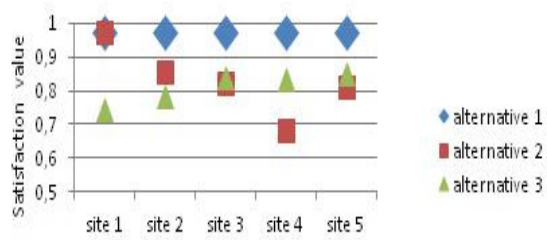

Fig. 6. Techno-Economic Objective

\subsection{Stage 2: Evaluation of Alternatives}

\section{Evaluation of Techno-Economic Objective (TEO):}

Technical and economical objective is assessed from cost (figure 3), technical capa-

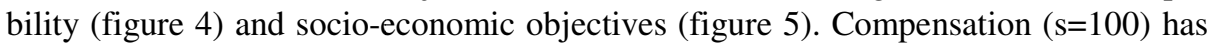
been made between these attributes. For alternative 1, poor satisfaction values of cost and technical objectives are compensated by the satisfaction of the socio-economic objective.

\section{Evaluation of Risk Objective}

Alternative 1 allows better control of risk factors, because in this case technology diffusion risk doesn't exist, supply disruption and product degradation risks are reduced because supplying raw materials has less value than supplying finite components. In the other hand, internal risks are more important in the case of internalization because more resources are needed. Consequently, human and machinery failures have more impact in this case.

\section{Local Performance Evaluation}

For each alternative, in order to assess the local performance, non compensatory aggregation $(\mathrm{s}=-100)$ is made between TEO and risk objective, and that for each site location. In the case study, figure 8 shows alternative 1 ranked 1 .

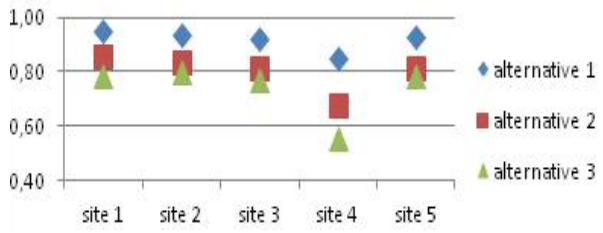

Fig. 7. Evaluation of risk objective 


\section{Global Performance Evaluation}

The global make or buy decision must be made by accounting for all local performance evaluations. Compensation $(s=100)$ is made between different sites. This implies that business 'strategic plan included that sites with negative financial results can be compensated by other sites with positive results. Figure 8 shows that alternative 1 presents in this case the best solution regarding the 5 sites. We note that all the 5 site locations are assumed to have the same importance : $\omega_{\text {site }}=0.2$.

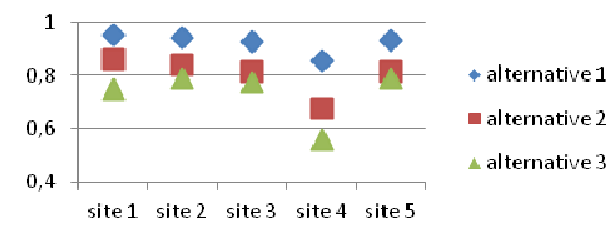

Fig. 8. Local Performance Evaluation

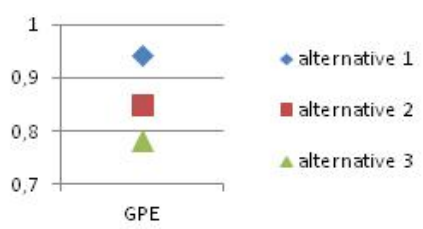

Fig. 9. Global Performance Evaluation

\section{Conclusion}

The paper aims to propose a structured decision model adapted for reconfigurable systems in multi-site context. Although the financial objective traditionally dominated the analysis of make or buy alternatives, this research demonstrates that is possible to consider strategic and technological issues in connection with the decision. The study allows considering specific characteristics of the mobile manufacturing systems and provides a model that takes into account a longer term vision.

There are additional areas to investigate. We considered that all providers and production sites were well identified. However, it depends on the commercial strategy of the firm. Uncertainty about future clients and likely suppliers should be considered.

\section{References}

1. Padillo, J.M., Diaby, M.: A multiple-criteria decision methodology for the make-or-buy problem. International Journal of Prduction Research (1999)

2. van de Water, H., van Peet, H.P.: A decision support model based on the Analytic Hierarchy Process for the Make or Buy decision in manufacturing. J. Purch. Supply Manag. 12(5), 258-271 (2006)

3. McIvor, R.T., Humphreys, P.K., McAleer, W.E.: A strategic model for the formulation of an effective make or buy decision. Manag. Decis. 35(2), 169-178 (1997)

4. Öncü, A.A., Oner, M.A., Başoğlu, N.: Make or Buy' Analysis for Local Manufacture or Import Decisions in Defense System Procurements Using AHP: The Case of Turkey. In: Proceedings of PICMET, p. 2 (2003)

5. McIvor, R.T., Humphreys, P.K.: A case-based reasoning approach to the make or buy decision. Integr. Manuf. Syst. 11(5), 295-310 (2000) 
6. ElMaraghy, H.A.: Flexible and reconfigurable manufacturing systems paradigms. Int. J. Flex. Manuf. Syst. 17(4), 261-276 (2006)

7. Bi, Z.M., Lang, S.Y.T., Shen, W., Wang, L.: Reconfigurable manufacturing systems: the state of the art. Int. J. Prod. Res. 46(4), 967-992 (2008)

8. Koren, Y., Shpitalni, M.: Design of reconfigurable manufacturing systems. J. Manuf. Syst. 29(4), 130-141 (2010)

9. Stillström, C., Jackson, M.: The concept of mobile manufacturing. J. Manuf. Syst. 26(3-4), 188-193 (2007)

10. Faris, C.W., Wind, Y., Institute, M.S., Robinson, P.J.: Industrial buying and creative marketing. Allyn \& Bacon, Boston (1967)

11. Collignan, A.: Méthode d'optimisation et d'aide à la décision en conception mécanique: Application à une structure aéronautique. Université Bordeaux I (2011)

12. Yager, R.R.: Generalized OWA Aggregation Operators. Fuzzy Optim. Decis. Mak. 3(1), 93-107 (2004)

13. Wagner, S.M., Bode, C.: An empirical examination of supply chain performance along several dimensions of risk. J. Bus. Logist. 29(1), 307-325 (2008)

14. Srinivasan, M., Mukherjee, D., Gaur, A.S.: Buyer-supplier partnership quality and supply chain performance: Moderating role of risks, and environmental uncertainty. Eur. Manag. J. 29(4), 260-271 (2011) 